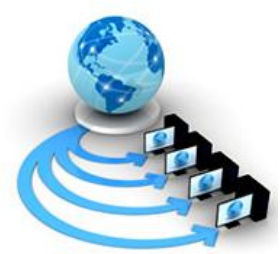

Volume 12, No. 3, May-June 2021

International Journal of Advanced Research in Computer Science

RESEARCH PAPER

Available Online at www.ijarcs.info

\title{
PID BASED ROOM TEMPERATURE CONTROL
}

\author{
Himangi Kumari \\ B.Tech.(ECE) \& minor degree in Cloud Computing,ASET \\ Amity University Haryana,India
}

\begin{abstract}
With the advancement in technology, the need has emerged to control various parameters like force, humidity, pressure and temperature. Out of these, temperature control has become an important necessity in today's world with the advent of various technologies in air conditioning and heating appliances. Many of these make use of PID controllers to maintain the temperature at the desired set point and prevent any overshoot. Here we have proposed PID based model which will be tuned manually to obtain the optimum values of the proportional, integral and derivative constants. Results are shown in terms of improved performance parameters (Rise Time, Overshoot and steady state error).
\end{abstract}

Keywords: PID, Temperature control, Microcontroller, Rise Time, Overshoot, steady state error.

\section{INTRODUCTION}

Many air conditioning and heating appliances generally come with a built in controller that maintains the temperature at a particular set point. These controllers are the PID controllers. PID control is more beneficial than the traditional on/off control since it gives more stability and faster control. There has not been much study in this regard as a lot of people are still unaware of the various tuning methods that can be implemented. Some of the tuning methods include manual tuning, Ziegler-Nichols, Tyreus Luyben and Cohen Coon. Instead of using the PID controller, designing of a PID circuit and tuning it manually gives more practical knowledge of the working of the PID control and helps to understand it better so that it can be used for a variety of other control schemes. This methodology can be used for many different applications and has a huge scope. To maintain a constant temperature, variety of devices are used which include temperature sensor LM35, operational amplifiers to control the gain and relay control. Since the microcontroller expects a digital input, an ADC is used to convert the analog input obtained by the sensor to digital.

\section{LITERATURE SURVEY}

In the work proposed by A.R. Laware et. al., manual tuning method had been preferred over other methods such as Ziegler-Nichols as it has large overshoot and settling time. Although Cohen- Coon method has comparatively less overshoot and settling time, it has lower stability. The plotting of the output was done by using MATLAB [1]. Temperature sensor was used to sense the temperature given as input to the microcontroller which has a brain of its own and contains CPU, timers and counters, interrupts, various ports for input/output on a single chip [2]. In the work of Jay Kumar et. al., the conventional PID algorithm had been used to create the temperature control loop to maintain the temperature at a targeted value by constantly monitoring the variables. Temperature oscillations and consumption of energy was reduced by maintaining a constant room temperature in spite of the constantly changing outdoor temperature. Simulink/MATLAB had been used to present the simulation results [3]. Robustness is the ability to tolerate changes occurring in parameters without making feedback unstable. The model parameters were randomly altered to investigate the robustness. Ankita Nayak et. al. used a three degree controller to monitor the temperature control. The steady state was achieved by the performance of the controller that included parameters like Proportional Band, Integral Time \& Derivative Time [4]. PID controller was used as it has a better and faster response since it predicts the future errors, reduces offset and has comparatively lesser overshoot than the proportional integral type controller. The transfer function was found by using process parameters determined by the system [5]. Combination of hardware and software had been used to design a closed loop control system for temperature using temperature sensor LM35, 89C51 microcontroller and appliance interface circuit. The temperature was compared with the set point and the switching of the appliance occurred corresponding to the increase or decrease in temperature [6]. In the experiment of Rajesh Singh et. al., a $1000 \mathrm{~W}(1 \mathrm{KW})$ heater was used as the heating element. Temperature sensor LM35 had been calibrated in Celsius (Centigrade) with linear resolution of $+10.0 \mathrm{mV} / \mathrm{C}$ scale factor. $16 \times 2 \mathrm{LCD}$ was used to display the set point and the process variable [7]. The traditional On/Off control had various disadvantages such as high deviations, more consumption of power, repetitive breakdowns and frequent failure. R. Suguna et. al. used in their experiment a PID controller for maintaining optimum temperature as it ensured lower consumption of power and lesser heat loss making it more efficient [8]. The system design was done by designing the hardware which included heater driver circuit design. The main program was implemented only after the initializing parameters such as $\mathrm{K}_{\mathrm{p}}$ : proportional gain, $\mathrm{K}_{\mathrm{i}}$ : integration coefficient, $K_{d}$ : derivative coefficient were found [9]. The design of the PID controller was made possible by 
simulating the model in MATLAB and getting the plots using LabView software. For designing virtual instruments and industrial applications, LabView had been used. Salim et. al. have preferred MATLAB for simulation as it is better for data manipulation, plotting of data and functions, interfaced easily with programs written in other languages [10]. In this research, variable resistors are used to adjust the set point which is displayed on the LCD using a start key to come out of the process variable loop which ensures that the set point remains undisturbed till the reset key is pressed. This eliminates the need for RF modules as used in the work of Rajesh Singh et. al. and enhances manual PID controller tuning methods and practical knowledge of the controller circuit [11].

\section{DESCRIPTION OF HARDWARE AND SOFTWARE}

Two circuits are implemented. One is for the Atmega 89C51 microcontroller and the other for PID control. Both circuits operate at a constant $+5 \mathrm{~V}$ supply given by two voltage regulator IC 7805. Two voltage regulators are used to reduce the load on the circuit and prevent heating. The $16 \times 2$ LCD displays the set point which is adjusted by the tone variable resistor and also displays the process variable, the temperature which is reached by the heating of the heating element of $1000 \mathrm{~W}$. The relay and the heating element operate on $220 \mathrm{~V}$ supply.

Relay is used for the switching of the element. When the relay is turned on, the element is switched off. Single pole relay is used connected to NC- normal connected. A transistor is connected through the relay to control switching.

A 555 Timer in astable mode is used to generate clock pulses provided to the ADC 0809 for converting analog input obtained by the temperature sensor LM35 (range $-55^{\circ}$ C

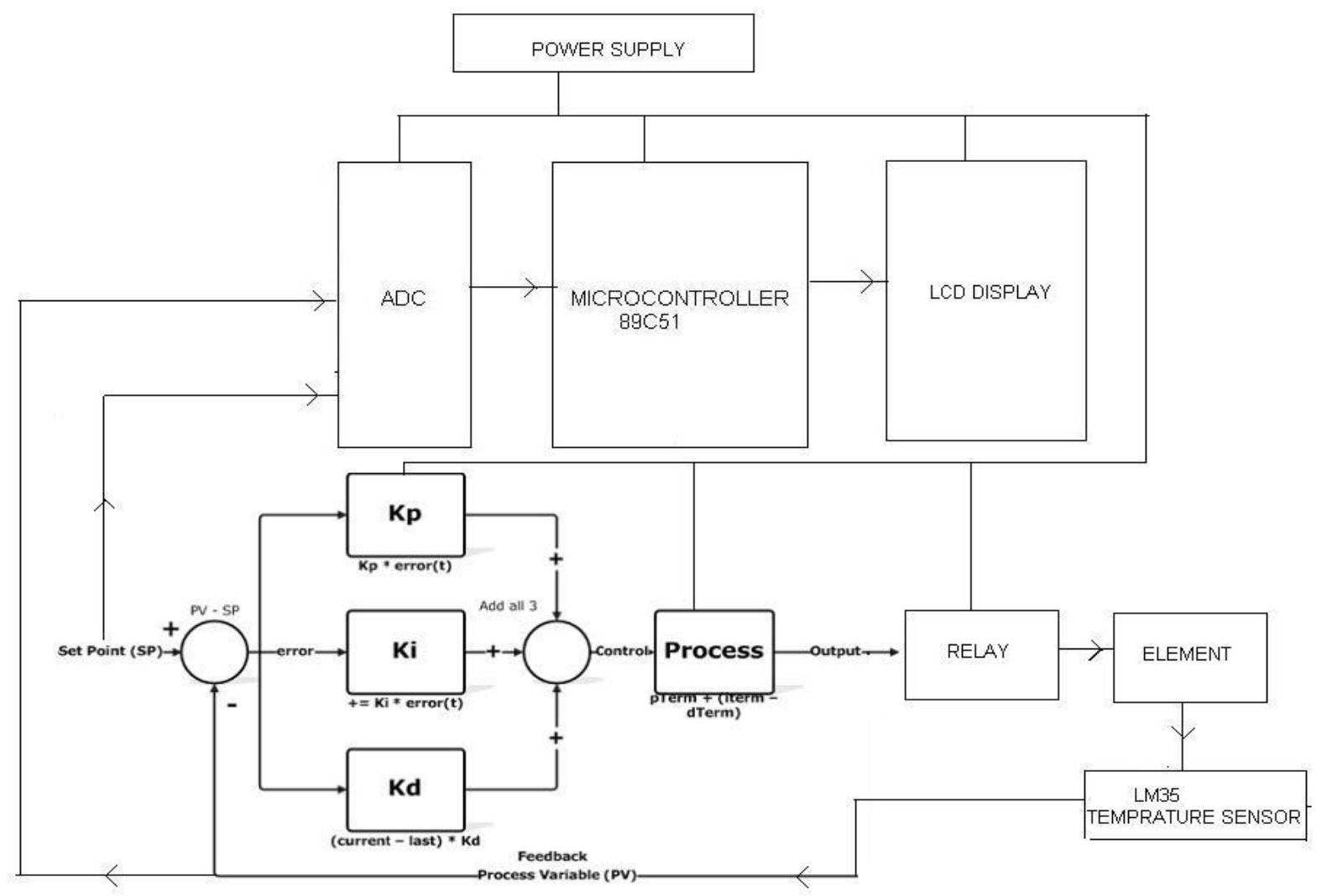

Fig. 1 Block Diagram

to $+150^{\circ} \mathrm{C}$ ) to digital which is then given to the microcontroller. 555 Timer is used instead of 8051 crystal oscillator as the ADC is very sensitive and requires frequency in $\mathrm{kHz}$. The temperature recorded by the sensor is fed to both the microcontroller and the PID circuit for comparing it with the set point. The reset key is used to reset the microcontroller. LED's are used as a power indicator and also to indicate when the relay is turned on.

Operational amplifier is a high gain device which has two differential inputs and one output. The PID circuit is made up of operational amplifiers. A transistor is a three terminal device used for amplification or switching. An aluminum sheet box is used to represent a room which consists of a heating element. A combination of electrolytic, ceramic capacitors and resistors is used in the circuit.

Keil $\mu$ Vision software is used for generating the hex file of the program in $\mathrm{C}$ language written using Embedded $\mathrm{C}$. $\mu$ Vision is easier to use as it provides a single environment for testing, verifying and optimization of the code. The presence of libraries, configuration files, source code templates and modules makes it user friendly. 


\section{METHODOLOGY}

To control the temperature of the heating element requires preventing overshoot of the process variable from the set point that can be adjusted using a tone variable resistor. A start key is used to come out of the loop of the process variable.

The circuit is set up first before connecting the element to prevent it from getting overly heated for ease of taking readings. The set point is kept above the normal room temperature. As the heating of the element takes place, the sensor is continuously detecting the temperature which is displayed on the LCD. When the temperature becomes equal to the set point or exceeds it, the relay is turned on and the element is turned off. When the temperature detected is lower than the set point, the relay is off and the heating of the element continues to take place.

This is accomplished by the PID circuit that uses operational amplifiers as comparator, proportional, integral, derivative control and buffer. The output of the P, I, D terms is added and is stored in the buffer. PID has feedback which is used for comparison of the process variable with the set point. The tuning of the PID is done manually using preset variable resistors. The error found out by the comparison is reduced to zero by the manual tuning of $\mathrm{P}, \mathrm{I}, \mathrm{D}$ terms.

Let transfer function of controller be denoted by $\mathrm{A}(\mathrm{t})$ given in equation (1).

$$
A(t)=K_{p} * e(t)+K_{i} \int e(t)+K_{d} * \frac{d}{d t} e(t)
$$

Where $\mathrm{K}_{\mathrm{p}}$ : proportional gain, $\mathrm{K}_{\mathrm{i}}$ : integral gain, $\mathrm{K}_{\mathrm{d}}$ : derivative gain.

Error is given by equation (2).

$$
e(t)=r(t)-y(t)
$$

where $\mathrm{e}(\mathrm{t})$ : error signal, $\mathrm{r}(\mathrm{t})$ : reference input signal \& $\mathrm{y}(\mathrm{t})$ : process output.
The output of LM 35 is found to be $10 \mathrm{mV} /{ }^{\circ} \mathrm{C}$ ( 0.01 Volts $)$ according to the data sheet. Therefore at $50^{\circ} \mathrm{C}$, we get $50 \times 0.01=0.5 \mathrm{~V}$ (approx.). Tuning of the op-amp. gain cannot be done in presence of the temperature sensor as it keeps on varying with the change in temperature. Therefore, we use a $10 \mathrm{k} \Omega$ variable resistor in place of the sensor while manually tuning the circuit. After the tuning is done, variable resistor is removed and temperature sensor LM35 is connected in its place. The output will accordingly increase or decrease in the same ratio as set using the variable resistor of $10 \mathrm{k} \Omega$. This value of the resistor is used so that minimum voltage also gives an output.

Proportional controller transfer function is given by equation (3).

$$
K_{P}=\frac{M(s)}{E(s)}
$$

where $\mathrm{K}_{\mathrm{p}}$ is the proportional gain, $\mathrm{m}$ is the manipulated variable and $\mathrm{e}$ is the deviation or error signal. $\mathrm{M}(\mathrm{s})$ is the Laplace transform of manipulated variable and $\mathrm{E}(\mathrm{s})$ is Laplace of error signal.

Determining $\mathrm{K}_{\mathrm{p}}$ : Using a screwdriver, the value of the variable resistor is varied till the time the relay gets switched on while keeping the $\mathrm{K}_{\mathrm{i}}, \mathrm{K}_{\mathrm{d}}$ terms equal to zero. This gives us the ideal value of $\mathrm{K}_{\mathrm{p}}$.

Integral controller transfer function is given by equation (4).

$$
\frac{M(s)}{E(s)}=\frac{K_{i}}{s}
$$

where $\mathrm{K}_{\mathrm{i}}$ is the integral gain inverse of which is the integral time or $\mathrm{T}_{\mathrm{i}}$.

Determining $\mathrm{K}_{\mathrm{i}}$ : Keeping $\mathrm{K}_{\mathrm{p}}$ fixed at the value set using the steps above and $K_{d}$ equal to zero, $K_{i}$ is varied. Using a screwdriver, the variable resistor for integral control is varied till the relay gets switched on and the LED indicating relay on starts glowing. This gives us the ideal value of $\mathrm{K}_{\mathrm{i}}$.

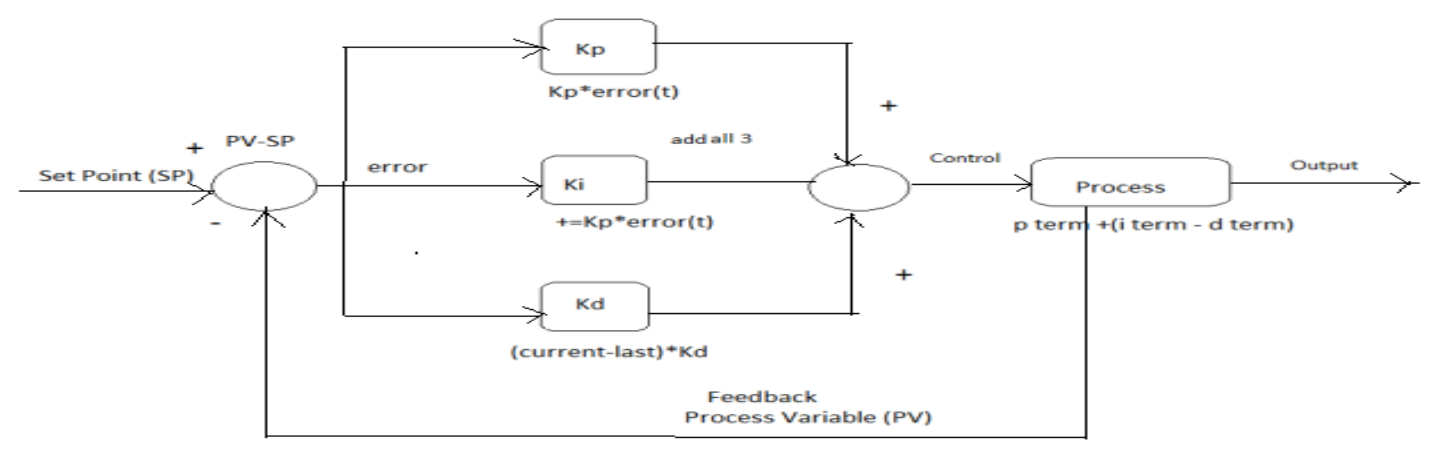

Fig.2 PID Controller

Derivative controller transfer function is given by equation (5).

$$
\frac{M(s)}{E(s)}=s K_{d}
$$

where $K_{d}$ is the derivative gain.
Determining $\mathrm{K}_{\mathrm{d}}$ : Keeping the values of $\mathrm{K}_{\mathrm{p}}$ and $\mathrm{K}_{\mathrm{i}}$ fixed as determined above and varying $\mathrm{K}_{\mathrm{d}}$ using a screwdriver at the variable resistor for derivative control, the value is adjusted till the relay turns on. This gives us the ideal value of $K_{d}$. 
Error is found at the proportional control, overshoot increases.

$\mathrm{I}$ term $=\mathrm{I}$ term $+\mathrm{K}_{\mathrm{i}} *$ error $(\mathrm{t})$

Integral control holds the error till it becomes zero.

$\mathrm{D}$ term $=($ current - last temperature $) * \mathrm{~K}_{\mathrm{d}}$

Derivative control records the difference between the current and the last temperature.

\section{RESULT}

Operational amplifier gain cannot be tuned in the presence of LM 35 as it keeps on varying with increase or decrease in temperature. Therefore, a $10 \mathrm{k} \Omega$ variable resistor is used instead of the sensor while manually tuning the circuit.Values of the variable resistors used to control gain of the operational amplifiers used in PID circuit:

$\mathrm{K}_{\mathrm{P}}=50 \mathrm{k} \Omega$

$\mathrm{K}_{\mathrm{i}}=54 \mathrm{k} \Omega$

$\mathrm{K}_{\mathrm{d}}=48 \mathrm{k} \Omega$

Depending on the values of P, I \& D calculated using the above constants and initial conditions (environment temperature $=43^{\circ} \mathrm{C}$, set point $=60^{\circ} \mathrm{C}$, step change $=60-43$ $=17^{\circ} \mathrm{C}$ ), we have found out the performance parameters for step change of $17^{\circ} \mathrm{C}$ as follows:

Rise Time $\left(\mathrm{t}_{\mathrm{r}}\right)=40 \mathrm{sec}$.

$1^{\text {st }}$ Overshoot $\left(\mathrm{m}_{\mathrm{p}}\right)=70^{\circ} \mathrm{C}$

Peak Time $\left(\mathrm{t}_{\mathrm{p}}\right)=1 \min$.

$1^{\text {st }}$ Undershoot $=57^{\circ} \mathrm{C}$

Settling Time $\left(\mathrm{t}_{\mathrm{s}}\right)=110 \mathrm{sec}$.

Steady state error $\left(\mathrm{e}_{\mathrm{ss}}\right)=1{ }^{\circ} \mathrm{C}$

\section{CONCLUSION}

The methodology used has given satisfying results. Steady state error has been minimized to $1^{\circ} \mathrm{C}$ and overshoot has been reduced. Faster control has been achieved using this method of manual tuning.

\section{FUTURE SCOPE \& APPLICATIONS}

Other parameters, for example- force and humidity can also be measured using different sensors on the same model as the ADC is an 8- channel interface and only two channels have been used for the set point and process variable. Six other sensors can be interfaced.

The relay used is a single pole relay with $n-p-n$ transistor as the driver. Using a relay driver IC, multiple relays can be used for control. The model can also be used to control the operation of a bulb or fan. In the case of fan, the working of the relay will be opposite to that of the heater, connecting it to NO- normal open. When the temperature becomes equal to the set point or exceeds it, the fan will start blowing.
It has proved more advantageous than simple on/off control by providing the user methods to tune the circuit as per requirement to get the desired results. This technique can be used in a variety of other applications such as temperature control in incubators using other technologies like genetic based algorithms, PLC's and Fuzzy Logic.

\section{REFERENCES}

[1] A.R. Laware, V.S. Bandal \& D.B. Talange; "Real Time Temperature Control System using PID Controller and Supervisory Control \& Data Acquisition System (SCADA)", International Journal of Application or Innovation in Engineering \& Management (IJAIEM), Vol. 2, Issue 2, (February 2013).

[2] Vikas Vats, Upendra Kumar - Amity University Gurgaon; "Speed Control of Fan Based on Room Temperature by using Programmable Logic Controller", International Journal of Recent Scientific Research, Vol. 6, Issue 4, (April 2015).

[3] Jay Kumar, Richa Kapoor, Brijebdra, Hemant, Jyoti; "Comparative Analysis of Room Temperature Controller using Fuzzy Logic \& PID”, Research India Publications, Advance in Electronic \& Electric Engineering, Vol. 3. Issue 7 (2013).

[4] Ankita Nayak, Mahesh Singh; "Study Of Tuning Of PID controller by using particle swarm optimization", International Journal for Innovative Research in Science and Technology (IJIRST), Vol. 1, Issue 4, (September 2014).

[5]SachinkumarHirenath, Nalini.C.Iyer and Raghavendra.M.Shet; "Comparison of Tuning Methods of PID Controllers for Non-Linear System”, International Journal of Recent Research in Electrical \& Electronics Engineering (IJRREEE) Vol. 3, Issue 1, (March 2016).

[6] Gaurav S. Ashara, Dipesh S. Vyas; "Design \& Simulation of Temperature Control of Chamber Based on Automatic Fan Speed Control", National Conference on Emerging Trends in Computer, Electrical \& Electronics (ETCEE- 2015), International Journal of Advance Engineering \& Research Development (IJAERD).

[7] Rajesh Singh, Piyush Kuchhal, Sushaban Choudhury \& Anita Gehlot; "Implementation \& Evaluation of Heating System using PID with Genetic Algorithm”, Indian Journal of Science and Technology, Vol. 8(5), March 2015.

[8] R. Suguna, V. Usha, Mr. S. Chidambaram; "A Temperature Control by Using PID Based Scr Control System", IOSR Journal of Electronics \& Communication Engineering (IOSR-JECE), Vol. 9, Issue 2, Ver. VIII (Mar. - Apr. 2014).

[9] AdhiKsatriaTheopaga, Achmad Rizal, Erwin Susanto; "Design and Implementation of PID control Based Baby Incubator", Journal of Theoretical and Applied Information Technology (JATIT), Vol. 70, No. 1, (December 2014)

[10] Salim, Sunil Kumar, Jyoti Ohri; "LabVIEW Based DC Motor \& Temperature Control Using PID Controller", International Journal of Advanced Research in Computer Science\& Software Engineering (IJARCSSE), Vol. 3, Issue 5, (May 2013).

[11] Rajesh Singh, Piyush Kuchhal, M.S. Yadav, Mahesh Kr. Sharma, Sushaban Choudhury \& Anita; "Optimization \& Implementation of Intelligent RF Remote Controlled Heater System", International Journal of Control \& Automation, Vol. 8, No. 5 (2015). 
DOl: http://dx.doi.org/10.26483/ijarcs.v12i3.6739

Volume 12, No. 3, May-June 2021

International Journal of Advanced Research in Computer Science

RESEARCH PAPER

Available Online at www.ijarcs.info 